RESENDE, G.M.; ALVARENGA, M.A.R.; YURI, J.E.; MOTA, J. H.; SOUZA, R.J.; RODRIGUES JÙNIOR, J.C. Produtividade e qualidade pós-colheita da alface americana em função de doses de nitrogênio e molibdênio. Horticultura Brasileira, Brasília, v.23, n.4, p.976-981, out-dez 2005.

\title{
Produtividade e qualidade pós-colheita da alface americana em função de doses de nitrogênio e molibdênio
}

\author{
Geraldo M. de Resende'; Marco Antônio R. Alvarenga²; Jony E. Yuri²; José Hortêncio Mota³; Rovilson \\ José de Souza ${ }^{2}$; Juarez C. Rodrigues Júnior ${ }^{4}$ \\ ${ }^{1}$ Embrapa Semi-Árido, C. Postal 23, 56300-000 Petrolina-PE.; ${ }^{2}$ UFLA. Depto. Agricultura, C. Postal 37, 37200-000 Lavras-MG; ${ }^{3}$ Centro \\ Universitário de Dourados, Depto. Ciências Agrárias, C. Postal 533, 79804-970, Dourados-MS; ${ }^{4}$ Agromax, R. Tiradentes, 12, 37750-000 \\ Machado-MG
}

\section{RESUMO}

O trabalho foi conduzido no município de Três Pontas (MG), de outubro a dezembro de 2002, para avaliar a influência de doses de nitrogênio e molibdênio nas características produtivas e qualidade pós-colheita da alface americana (Lactuca sativa L.). Utilizou-se o delineamento de blocos ao acaso em arranjo fatorial 4 x 5, compreendendo quatro doses de nitrogênio em cobertura adicionais à dose aplicada pelo produtor de $60 \mathrm{~kg} / \mathrm{ha}$ de $\mathrm{N}(0 ; 60 ; 120$ e $180 \mathrm{~kg} / \mathrm{ha}) \mathrm{e}$ cinco doses de molibdênio via foliar $(0,0 ; 35,1 ; 70,2 ; 105,3$ e 140,4 $\mathrm{g} / \mathrm{ha}$ ) e três repetições. O maior peso fresco total foi obtido com a dose de $86,9 \mathrm{~kg} / \mathrm{ha}$ de nitrogênio em cobertura e $87,4 \mathrm{~g} / \mathrm{ha}$ de molibdênio. Com relação ao peso fresco comercial a dose de 89,1 $\mathrm{kg} / \mathrm{ha}$ de nitrogênio em cobertura propiciou a maior resposta, sendo para molibdênio a máxima produtividade alcançada com a dose de $94,2 \mathrm{~g} / \mathrm{ha}$. As doses de 85,3 kg/ha de nitrogênio em cobertura e 72,9 $\mathrm{g} /$ ha de molibdênio proporcionaram a maior circunferência de cabeça comercial. Não se observou efeito significativo dos tratamentos para comprimento do caule e na conservação pós-colheita. As doses de $89,9 \mathrm{~kg} / \mathrm{ha}$ de $\mathrm{N}$ em cobertura e 77,2 g/ha de Mo em pulverização foliar propiciaram a maior porcentagem de matéria seca.

Palavras-chave: Lactuca sativa L., massa fresca, nutrição, armazenamento.

\begin{abstract}
Yield and postharvest quality of summer growing crisphead lettuce as affected by doses of nitrogen and molybdenum

The influence of nitrogen and molybdenum doses was evaluated on the productive characteristics and postharvest quality of crisphead lettuce (Lactuca sativa L.), at Três Pontas, Minas Gerais State, Brazil, from October to December 2002. A randomized complete block design in a 4 x 5 factorial arrangement with three replications was used. The factorial consisted of four doses of nitrogen $(0 ; 60 ; 120$ and $180 \mathrm{~kg} / \mathrm{ha}$ ) in top dressing, in addition to the usual farmers doses $(60 \mathrm{~kg} / \mathrm{ha})$, and five doses of molybdenum in foliar application $(0.0$; $35.1 ; 70.2 ; 105.3$, and $140.4 \mathrm{~g} / \mathrm{ha})$. The highest total fresh weight was obtained with the doses of $86.9 \mathrm{~kg} / \mathrm{ha}$ of nitrogen in top dressing and $87.4 \mathrm{~g} / \mathrm{ha}$ of molybdenum. Highest commercial fresh weight was obtained using the doses of $89.1 \mathrm{~g} / \mathrm{ha}$ of nitrogen in top dressing, while the doses of $94.2 \mathrm{~g} / \mathrm{ha}$ of molybdenum resulted in the highest yield. The doses of $85.3 \mathrm{~kg} / \mathrm{ha}$ of nitrogen in top dressing and 72.9 $\mathrm{g} / \mathrm{ha}$ of molybdenum were the best for highest commercial head circumference. There was no significant effect of the treatments on stem length and post-harvest conservation. The highest percentage of dry matter was obtained with the doses of $89.9 \mathrm{~kg} / \mathrm{ha}$ of $\mathrm{N}$ in top dressing and $77.2 \mathrm{~g} / \mathrm{ha}$ of Mo in foliar spray.
\end{abstract}

Keywords: Lactuca sativa L., fresh weight, nutrition, storage.

(Recebido para publicação em 21 de março de 2005 e aceito em 5 de agosto de 2005)

\begin{abstract}
A alface americana, tipo repolhuda "Crisphead lettuce", vem adquirindo importância crescente, principalmente, na região de Lavras. O plantio deste tipo de alface visa, principalmente, atender as redes fast food, como a MacDonald's, com mais de 30 produtores em diversos municípios do sul de Minas Gerais, cultivando cerca de 1800 ha por ano, totalizando aproximadamente 10500 toneladas desta folhosa (YURI, 2000). Sua larga adaptação às condições climáticas diversas, a possibilidade de cultivos sucessivos no mesmo ano, a baixa suscetibilidade a pragas e doenças e a comercialização segura, fazem desta cultura a preferida pelos olericultores (RICCI, 1993), que a cultivam em condições de campo a céu
\end{abstract}

aberto, em cultivo protegido (estufas) ou em hidroponia (solução nutritiva).

A adubação constitui uma das práticas agrícolas mais caras e de maior retorno econômico, resultando em maiores rendimentos e em produtos mais uniformes e de maior valor comercial (RICCI et al., 1995).

Sendo a alface uma cultura composta basicamente por folhas, esta responde muito à adubação nitrogenada. A deficiência de nitrogênio retarda o crescimento da planta e induz ausência ou má formação da cabeça, as folhas mais velhas tornam-se amareladas e desprendem-se com facilidade. Entretanto, quando aplicado em demasia, em adubação de cobertura, no último terço do ciclo, as cultivares que formam cabeça apresentam menor firmeza, o que poderá ser prejudicial à comercialização (GARCIA et al., 1982).

Nos sistemas biológicos o molibdênio é constituinte de pelo menos cinco enzimas catalisadoras de reações. Três destas enzimas (redutase do nitrato, nitrogenase e oxidase do sulfito) são encontradas em plantas (GUPTA; LIPSETT, 1981). A função mais importante do molibdênio nas plantas está relacionada com o metabolismo do nitrogênio. A redutase do nitrato ou nitratoredutase é uma flavoproteína que possui Mo como grupo prostético e cuja síntese é induzida pela presença de Mo e $\mathrm{NO}_{3}{ }^{-}$no meio (MALAVOLTA, 1980). Esta enzima catalisa a redução biológica do $\mathrm{NO}_{3}^{-}$a $\mathrm{NO}_{2}^{-}$, que é o primeiro pas- 
so para a incorporação do nitrogênio, como $\mathrm{NH}_{2}$, em proteínas (DECHEN et al., 1991). Por outro lado, evita o acúmulo de $\mathrm{NO}_{3}^{-}$em plantas alimentícias e forragens, impedindo a combinação do mesmo com a hemoglobina do sangue e a produção de metahemoglobina que, por não funcionar como transportadora de $\mathrm{O}_{2}$, causa deficiência de oxigênio em pessoas e animais (MALAVOLTA, 1980; OLIVEIRA, 1980). A deficiência de molibdênio em brássicas também está associada a uma acumulação de nitratos nas folhas (NOGUEIRA et al., 1983).

No Brasil observa-se a necessidade de maiores pesquisas sobre doses de fertilizantes a serem utilizadas, adequadas às diferentes cultivares, regiões e épocas de plantio. Além disto, na ansiedade de obter maior produtividade, o olericultor aplica em excesso, elementos minerais, resultando muitas vezes em distúrbios nutricionais nas plantas, além de acarretar aumento do custo de produtividade.

A aplicação de nitrogênio via solo aliada à aplicação de molibdênio via foliar, pode ser uma prática que venha a melhorar a fertilização desta cultura, com o uso mais racional do nitrogênio, e por uma maior atividade da enzima redutase do nitrato, através do uso da adubação molíbdica. O objetivo deste trabalho foi avaliar os efeitos de doses de nitrogênio em cobertura e molibdênio via foliar nas características produtivas e qualidade pós-colheita no comportamento da alface americana em cultivo de verão.

\section{MATERIAL E MÉTODOS}

O experimento foi conduzido no município de Três Pontas, sul de Minas Gerais, na Fazenda Carapuça II do produtor José Cláudio Nogueira, à altitude de $870 \mathrm{~m}$, situado a $21^{\circ} 22^{\prime} 00^{\prime \prime}$ de longi-

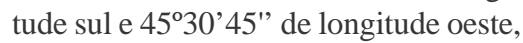
em um Latossolo Vermelho Distroférrico de textura argilosa. O clima da região é caracterizado por temperatura média anual variando de $15,8^{\circ} \mathrm{C}$ no mês mais frio, a $22,1^{\circ} \mathrm{C}$ no mês mais quente; a precipitação média anual é de $1.529,7 \mathrm{~mm}$ e a umidade relativa do ar é de 76,2\%. A análise do solo onde foi instalado o experimento apresentou as seguintes características químicas: $\mathrm{K}=70,0 \mathrm{mg} \mathrm{dm}^{-3} ; \mathrm{P}=78,0 \mathrm{mg}$ $\mathrm{dm}^{-3} ; \mathrm{Ca}=4,1 \mathrm{cmol}_{\mathrm{c}} \mathrm{dm}^{-3} ; \mathrm{Mg}=0,8 \mathrm{cmol}_{\mathrm{c}}$ $\mathrm{dm}^{-3} ; \mathrm{Al}=0,0 \mathrm{cmol}_{\mathrm{c}} \mathrm{dm}^{-3} ; \mathrm{H}+\mathrm{Al}=2,3$ $\mathrm{cmol}_{\mathrm{c}} \mathrm{dm}^{-3} ; \mathrm{Zn}=0,8 \mathrm{mg} \mathrm{dm}^{-3} ; \mathrm{Fe}=25,0$ $\mathrm{mg} \mathrm{dm}{ }^{-3} ; \mathrm{Mn}=14,2 \mathrm{mg} \mathrm{dm}^{-3} ; \mathrm{Cu}=1,0$ $\mathrm{mg} \mathrm{dm}{ }^{-3} ; \mathrm{B}=0,3 \mathrm{mg} \mathrm{dm}^{-3} ; \mathrm{pH} \mathrm{em} \mathrm{H}_{2} \mathrm{O}=$ 6,0 e matéria orgânica $=2,4$ dag kg $^{-1}$.

$\mathrm{O}$ delineamento experimental foi de blocos ao acaso no esquema fatorial $4 \mathrm{x}$ 5 , compreendendo quatro doses de nitrogênio em cobertura adicionais a dose aplicada pelo produtor de $60 \mathrm{~kg} / \mathrm{ha}$ de nitrogênio $(0 ; 60 ; 120$ e 180 kg/ha) e cinco doses de molibdênio via foliar $(0,0 ; 35,1 ; 70,2 ; 105,3$ e $140,4 \mathrm{~g} / \mathrm{ha})$ e três repetições, perfazendo um total de 20 tratamentos. A uréia foi utilizado como adubo nitrogenado e como fonte de molibdênio o molibdato de sódio. A uréia foi aplicada em cobertura aos 10 ; 20 e 30 dias após o transplante em 40, 30 e $30 \%$, respectivamente, da dose avaliada. As doses em cobertura de uréia por parcela por planta foram previamente diluídas em água pura, aplicando-se $10 \mathrm{ml}$ da solução, lateralmente a cada planta. O molibdato de sódio foi aplicado aos 21 dias após o transplante através de pulverizador costal manual capacidade de $4 \mathrm{~L}$ em máxima pressão, gastando-se $300 \mathrm{~L}$ de calda/ha.

O preparo do solo constou de aração, gradagem e levantamento dos canteiros a 0,20 m de altura. As mudas foram obtidas em bandejas multicelulares de 288 células cada uma, preenchidas com substrato comercial (Plantmax), sendo o transplante feito aos 25 dias após o semeio, utilizando-se a cultivar Raider que apresenta um ciclo de 48 a 50 dias após o transplante, com peso médio de planta entre 700 e 1200 g, folhas de coloração verde-clara mais duras e boa tolerância ao pendoamento (YURI, 2000).

As parcelas experimentais constituíram-se de canteiros com quatro linhas de 2,1 m de comprimento espaçadas de $0,30 \mathrm{~m}$, sendo entre plantas de 0,35 m. As linhas centrais formaram a área útil, retirando-se duas plantas em cada extremidade. Foi instalada, em toda a área, uma estrutura de proteção, constituída de túneis altos com 2,0 m de altura, cobrindo dois canteiros por túnel, constituído de tubos de ferro galvanizados, coberta com filme plástico transparente de baixa densidade, aditivado com antiUV, de 100 micras de espessura, sendo os canteiros revestidos com filme plástico preto "mulching", de $4 \mathrm{~m}$ de largura e 35 micras de espessura.

A adubação básica de plantio, de acordo com análise do solo, foi de 1500 $\mathrm{kg} / \mathrm{ha}$ de formulado $02-16-08$ e $1000 \mathrm{~kg} /$ ha de superfosfato simples. Após os adubos serem incorporados ao solo, instalou-se em cada canteiro duas linhas de tubo gotejador, com emissores espaçados a cada $30 \mathrm{~cm}$ e com vazão de 1,5 L/ h. As adubações de cobertura foram realizadas através de fertirrigações diárias, totalizando $30 \mathrm{~kg} / \mathrm{ha}$ de $\mathrm{N}$ e $60 \mathrm{~kg}$ de $\mathrm{K}$, utilizando como fontes uréia e cloreto de potássio (COMISSÃO..., 1999).

A cultura foi mantida no limpo por meio de capinas manuais, quando necessárias, e o controle fitossanitário adotado foi o método padrão utilizado pelo produtor, com pulverizações semanais com produtos à base de oxicloreto de cobre, iprodione, procimidone e piretróides.

O transplante das mudas foi realizado em 28/10/2002. A colheita foi feita em 09/12/2002, quando as plantas apresentaram-se completamente desenvolvidas sendo avaliadas a massa fresca total e comercial (g/planta); circunferência e comprimento do caule da parte comercial em cm (cabeça), percentagem de matéria seca da parte comercial. Para o peso da matéria seca da parte comercial, as amostras $( \pm 300 \mathrm{~g})$ foram lavadas em água corrente e destilada e secas em estufa com circulação forçada de ar, a 65$70^{\circ} \mathrm{C}$, até peso constante. Os dados de percentagem de matéria seca foram transformados em arco-seno $\sqrt{P / 100}$. A conservação pós-colheita foi avaliada utilizando-se amostra de duas cabeças comerciais de alface, avaliadas aos 7; 14; 21 e 28 dias, em câmara frigorífica a $5 \pm 2{ }^{\circ} \mathrm{C}$ e umidade relativa em torno de $90 \%$, através de notas (nota $1=$ cabeças comerciais extremamente deterioradas; nota $2=$ cabeças comerciais deterioradas; nota $3=$ cabeças comerciais moderadamente deterioradas; nota $4=$ cabeças comerciais levemente deterioradas e nota $5=$ cabeças comerciais sem deterioração), sendo utilizados três avaliadores e obtida a média das notas. 


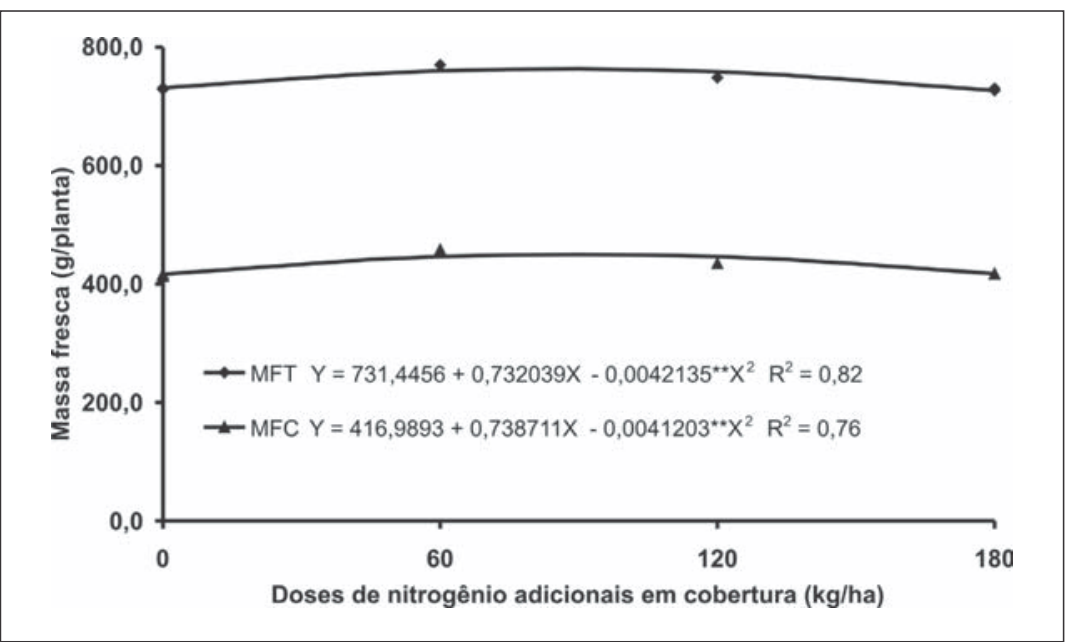

Figura 1. Massa fresca total (MFT) e comercial (MFC) de alface americana em função de doses de nitrogênio em cobertura. Três Pontas (MG), UFLA, 2002.

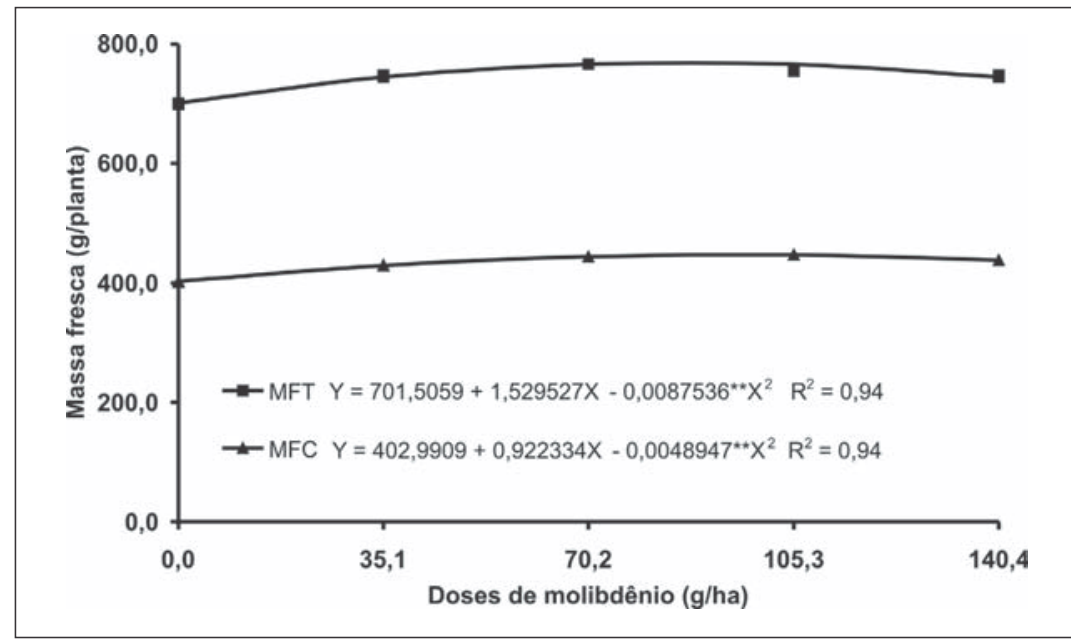

Figura 2. Massa fresca total (MFT) e comercial (MFC) de alface americana em função de doses de molibdênio. Três Pontas (MG), UFLA, 2002.

Os dados coletados foram submetidos à análise de variância e regressão com base no modelo polinomial ao nível de $5 \%$ de probabilidade.

\section{RESULTADOS E DISCUSSÃO}

Houve efeito significativo e independente para doses de nitrogênio e de molibdênio para peso da massa fresca total e comercial da parte aérea. Com relação ao peso fresco total, os dados relativos a doses de nitrogênio foram ajustados a um modelo quadrático, no qual a dose de $86,9 \mathrm{~kg} / \mathrm{ha}$ de nitrogênio em cobertura propiciou o maior rendimento, com 763,2 g/planta de massa ha de nitrogênio. Furtado (2001), em plantio de agosto, não encontrou diferenças significativas entre tratamentos, avaliando doses acima de 148,0 kg/ha de nitrogênio.

Comparando os dados obtidos no presente experimento com trabalhos realizados por McPharlin et al. (1995) na Austrália, utilizando 0,0 a $550,0 \mathrm{~kg} / \mathrm{ha}$ de $\mathrm{N}$, verifica-se que a dose correspondente à máxima produção de massa fresca foi inferior a dose de 288,0 e $344 \mathrm{~kg} / \mathrm{ha}$ de $\mathrm{N}$ encontrada por estes autores, em dois anos de estudo. Deve-se salientar ainda que, o médio teor de matéria orgânica, 2,1 dag/kg, do solo utilizado no presente experimento provavelmente contribuiu para uma menor resposta à adubação nitrogenada. Segundo Thompson e Doerge (1996b), nos Estados Unidos, os agricultores utilizam doses que variam de 224,0 a 370,0 kg/ha.

Quanto à aplicação de molibdênio também ajustou-se um modelo quadrático, no qual a dose de $87,4 \mathrm{~g} / \mathrm{ha}$ de molibdênio promoveu o maior ganho em termos de rendimento de massa fresca total com 768,4 g/planta (Figura 2). Também em plantio de verão, Yuri et al. (2004a), constataram efeito quadrático no qual a dose de $235,0 \mathrm{~g} / \mathrm{ha}$ de molibdênio proporcionou a maior produtividade total por planta, $15,2 \%$ superior à testemunha sem aplicação.

Com relação à massa fresca comercial, os dados relativos a doses de nitrogênio foram ajustados a um modelo quadrático, no qual a dose de $89,1 \mathrm{~kg} /$ ha de nitrogênio em cobertura propiciou a maior resposta, com 450,1 g/planta de massa fresca comercial (Figura 1). Levando-se em consideração que o produtor utilizou um total $60,0 \mathrm{~kg} / \mathrm{ha}$ de N, a necessidade para se obter a máxima produtividade comercial foi de $149,1 \mathrm{~kg} /$ ha de nitrogênio. Furtado (2001) não encontrou diferenças significativas, avaliando doses acima 148,0 kg/ha de nitrogênio. Este resultado é inferior à dose de $168,0 \mathrm{~kg} / \mathrm{ha}$ de $\mathrm{N}$ para máxima produtividade de alface americana, informado por Mcpharlin et al. (1995), relatando diferentes autores, para as condições do Arizona, tanto em cultivos na primavera como no outono. Assim como está próximo à dose de $155 \mathrm{~kg} / \mathrm{ha}$ de $\mathrm{N}$, encontrados por Tei et al. (2000), para alface tipo lisa e "Butterhead". 
Pela Figura 2 observa-se para doses de molibdênio, um efeito quadrático com ponto de máxima produtividade de massa fresca comercial na dose de 94,2 $\mathrm{g} / \mathrm{ha}$ (445,8 g/planta). Com o incremento das doses de molibdênio em função das épocas de aplicação, Yuri et al. (2004a), verificaram efeitos quadráticos para peso fresco comercial, tendo a dose de 212,0 g/ha de molibdênio proporcionado o maior rendimento quando aplicado aos 21 dias após o transplante. Resultados positivos da aplicação de molibdênio na cultura da alface são relatados por Fontes et al. (1982) e Zito et al. (1994), que observaram aumento médio de $31,0 \%$ e $24,1 \%$, na produção comercial de alface com a aplicação de molibdênio.

A circunferência da parte comercial (cabeça) é uma das principais características para a alface americana, considerando a preferência do consumidor para a aquisição do produto (BUENO, 1998). Assim como para as características anteriores, para a circunferência da cabeça comercial, os fatores estudados apresentaram efeitos independentes. Ajustou-se um modelo quadrático com ponto de máxima circunferência para a dose de $85,3 \mathrm{~kg} / \mathrm{ha}$ de nitrogênio em cobertura (Figura 3), que proporcionou uma circunferência de $37,5 \mathrm{~cm}$, pouco inferior à variação encontrada por Yuri (2000) sob condições de verão, para diferentes cultivares, entre 40,1 a 42,9 cm. Resultados estes similares aos relatados por Kalil (1992), Alves (1996) e Bueno (1998), que observaram significativo incremento da circunferência da cabeça comercial com aumento das doses de nitrogênio.

Quando se refere a doses de molibdênio, constata-se um efeito significativo no qual a dose de 72,9 g/ha (Figura 4), proporcionada pelo modelo quadrático ajustado à equação de regressão, alcançou a maior circunferência da cabeça. Yuri et al. (2004a), relatam a dose de 220,0 g/ha de molibdênio como a que promoveu a maior circunferência da cabeça comercial, sendo as melhores épocas de aplicação aos 14 e 21 dias, que não mostraram diferenças significativas entre si. Uma resposta diferencial entre espécies à disponibilidade de molibdênio tem sido relatada por

Tabela 1. Equações de regressão para circunferência da cabeça comercial $(\mathrm{cm})$ e teor de matéria seca $(\%)$ em função das doses de nitrogênio $(\mathrm{N})$ adicionais em cobertura e de molibdênio (Mo). Três Pontas (MG), UFLA, 2002.

\begin{tabular}{lll}
\hline Características & Equações de regressão & \\
\hline \multirow{2}{*}{ Circunferência da cabeça } & $(\mathrm{N}) \mathrm{Y}=36,5163+0,022827 X-0,0001338^{* *} \mathrm{X}^{2}$ & $\mathrm{R}^{2}=0,98$ \\
& $(\mathrm{Mo}) \mathrm{Y}=36,2340+0,033387 X-0,0002290^{* *} X^{2}$ & $R^{2}=0,98$ \\
\hline \multirow{2}{*}{ Teor de matéria seca11 } & $(\mathrm{N}) \mathrm{Y}=10,2509+0,007765 X-0,0000432^{* *} \mathrm{X}^{2}$ & $\mathrm{R}^{2}=0,80$ \\
& $(\mathrm{Mo}) \mathrm{Y}=10,1054+0,013418 X-0,0000869^{* *} X^{2}$ & $R^{2}=0,68$ \\
\hline
\end{tabular}

${ }^{1}$ Dados transformados em arco-seno $\sqrt{P / 100}$.

** Significativo ao nível de $1 \%$ pelo teste de $\mathrm{F}$.

Malavolta e Kliemann (1985), sendo que há uma alta resposta em alface, assim como em brócolos, beterraba, couve-flor, espinafre e repolho.

Não se observou efeitos significativos dos tratamentos para comprimento do caule. Menores comprimentos de caule são desejáveis para a alface americana, principalmente quando destinada à indústria de beneficiamento, devendo ser bastante reduzido, proporcionando menores perdas durante o processamento. O caule excessivamente comprido acarreta menor compacidade da cabeça e dificulta o beneficiamento, afetando a qualidade final do produto (YURI et al., 2002; RESENDE et al., 2003b). Na prática, caules até $6,0 \mathrm{~cm}$ seriam os mais adequados, sendo aceitáveis até o patamar de 9,0 cm e inaceitáveis ou menos recomendados para processamento acima disto. Neste contexto, as doses de nitrogênio apresentaram uma variação entre 7,2 e $7,4 \mathrm{~cm}$ e as doses de molibdênio entre 7,0 e 7,4 cm, próximos ao nível adequado e dentro do limite aceitável.

Salienta-se que há uma tendência da alface americana em condições de cultivo de verão apresentar maiores comprimentos de caule comparativamente ao cultivo de inverno onde esta se mostra perfeitamente adaptada. Resultados semelhantes para doses de molibdênio foram encontrados por Yuri et al. (2004a), que não constataram efeitos significativos para comprimento do caule. Dados não concordantes foram obtidos por Bueno (1998) que verificou um aumento linear no comprimento do caule com o incremento das doses de nitrogênio.

Para o teor de matéria seca da parte comercial, a análise de variância reve- lou diferenças significativas, tanto para doses de nitrogênio como para doses de molibdênio, agindo de forma independente (Tabela 1). Estimou-se que a dose de $89,9 \mathrm{~kg} / \mathrm{ha}$ de $\mathrm{N}$ em cobertura adicional a dose aplicada pelo produtor de $60,0 \mathrm{~kg} / \mathrm{ha}$, propiciaria o maior retorno em termos de porcentagem de matéria seca da planta (Tabela 1). Este resultado é similar aos encontrados por Alves (1996) e Fontes et al. (1997), que obtiveram efeito positivo para a matéria seca da alface cultivar Regina 440 e Brasil 202, em resposta à adição de nitrogênio. Todavia, Furtado (2001), utilizando a mesma cultivar, obteve um efeito linear negativo como o incremento das doses de nitrogênio.

A conservação pós-colheita das cabeças comerciais avaliada em câmara frigorífica aos 7, 14; 21 e 28 dias após a colheita, não evidenciaram diferenças significativas entre doses de nitrogênio e molibdênio. Aos sete dias após a colheita as cabeças comerciais apresentavam-se perfeitas, sem deterioração (nota 5,0). Já aos 14 dias verificaram-se para doses de nitrogênio em cobertura e molibdênio notas médias de 3,7 e 3,8, notas estas próximas a 4,0 que caracterizam cabeças comerciais levemente deterioradas. Obteve-se aos 21 dias após a colheita, notas de e 3,1 e 3,0 (moderadamente deterioradas), respectivamente, para nitrogênio e molibdênio. Cerca de 28 dias após a colheita as cabeças já se apresentavam deterioradas, obtendo notas médias de 2,0 e 2,1, respectivamente, para doses de nitrogênio em cobertura e molibdênio. Está é uma característica de grande importância em alface americana visto que o produto final é processado e armazenado em câmaras frigoríficas para posterior distri- 
buição. Portanto, uma maior conservação do produto após sua colheita é desejável e de considerável relevância. Não foram encontrados relatos na literatura de uma possível contribuição do nitrogênio e do molibdênio em aumentar a conservação da alface americana. No entanto, há relatos de pequeno efeito na perda de peso pela adição de nitrogênio (POULSEN et al., 1994), assim como efeitos não significativos (SANCHEZ et al., 1988) e de melhor conservação pós-colheita com a utilização de adubação com outros nutrientes como silício e boro (RESENDE et al. 2003a; YURI et al., 2003 e 2004b).

A duração do ciclo vegetativo da semeadura à colheita, correspondeu a 67 dias, enquanto Furtado (2001) encontrou para o transplante no final de agosto, 73 dias de ciclo cultural. Segundo Whitaker e Ryder (1974), a temperatura é o fator ambiental que mais influencia na formação de cabeça uma vez que está relacionada com o pendoamento. A origem Mediterrânea da alface explica este comportamento, já que nesta região as temperaturas médias oscilam entre $10 \mathrm{e}$ $20^{\circ} \mathrm{C}$ (LINDQUIVIST, 1960 ). Segundo Jackson et al. (1996), a alface americana requer, como temperatura ideal para o desenvolvimento, $23^{\circ} \mathrm{C}$ durante o dia e $7^{\circ} \mathrm{C}$ à noite. Temperaturas muito elevadas podem provocar queima das bordas, formar cabeças pouco compactas, e também contribuir para ocorrer deficiência de cálcio, conhecido como tip-burn. No presente experimento não se observou qualquer ocorrência de tipturn. No entanto, a maior precocidade que ocorre no verão, contribuiu para a formação de cabeças menos compactas, o que foi visualmente detectado, assim como pode-se verificar um maior comprimento do caule, comparativamente a época de melhor adaptação da cultura que é no inverno.

Pelos resultados obtidos pode-se concluir que as doses de nitrogênio em cobertura e de molibdênio foliar influenciaram positivamente o peso fresco total, comercial e a circunferência da cabeça comercial, não sendo observado efeito significativo sobre o comprimento do caule e a conservação pós-colheita da alface americana.

\section{LITERATURA CITADA}

ALVES, D.R.B.A. Efeito de adubação nitrogenada via fertirrigação e aplicação de forma convencional na produção de alface (Lactuca sativa L.) em estufa. 1996. 76 f. Dissertação (Mestrado em Fitotecnia) - Universidade Estadual Paulista, Botucatu, SP.

BUENO, C.R. Efeito da adubação nitrogenada em cobertura via fertirrigação por gotejamento para a cultura da alface tipo americana em ambiente protegido. 1998. 54 f. Dissertação (Mestrado em Fitotecnia) - Universidade Federal de Lavras, Lavras, MG.

COMISSÃO DE FERTILIDADE DE SOLO DO ESTADO DE MINAS GERAIS Recomendações para o uso de corretivos e fertilizantes em Minas Gerais: 5'Aproximação: Viçosa, 1999. 359 p.

DECHEN, A.R.; HAAG, H.P.; CARMELLO, Q.A.C. Funções de micronutrientes nas plantas. In: FERREIRA, M.E.; CRUZ. M.C.P. (Ed.). Micronutrientes na agricultura. Piracicaba: POTAFOS/CNPq, 1991. p.65-78.

FONTES, P.C.R.; PEREIRA, P.R.G.; CONDE, R.M. Critical chlrophill, total nitrogen, and nitratenitrogen in leaves associated to maximum lettuce yield. Journal of Plant Nutrition, v.20, n.9, p.10611068, 1997.

FONTES, R.R.; LIMA, J.A.; TORRES, A.C.; CARRIJO, O.A. Efeito da aplicação de Mg, B, $\mathrm{Zn}$ e Mo na produção de alface. Pesquisa Agropecuária Brasileira, Brasília, v.17, n.2, p.171175, 1982

FURTADO, S.C. Nitrogênio e fósforo na produtividade e nutrição mineral de alface americana cultivada em sucessão ao feijão após o pousio da área. 2001. 78 f. Dissertação (Mestrado em Fitotecnia) - Universidade Federal de Lavras, Lavras, MG

GARCIA, L.L.C.; HAAG, H.P.; NETO, V.D. Nutrição mineral de hortaliças-Deficiências de macronutrientes em alface (Lactuca sativa L.), $c v$. Brasil 48 e Clause's Aurélia. Anais da Escola Superior de Agricultura Luiz de Queiroz, Piracicaba, v.39, n.1, p.349-362, 1982.

GUPTA, U.C.; LIPSETT, J. Molybdenum in soils, plants, and animals. Advances in Agronomy, v.34, p.73-115, 1981.

JACKSON, L.; MAYBERRY, K.; LAEMMLEN, F.; KOIKE, S.; SCHLUBACK, K. Iceberg lettuce production in California. Disponível em: <http// www.vegetablecrops.ucdavis>. Acesso em: 24 out. 1999.

KALIL, A.J.B. Comparação entre adubação nitrogenada via fertirrigação por gotejamento $e$ a aplicação convencional na produtividade da alface (Lactuca sativa L.). 1992. 60 f. Dissertação (Mestrado em Engenharia Agrícola) - Universidade Federal de Viçosa, Viçosa, MG.

LINDQUIVIST, K. On the origin of cultivated lettuce. Hereditas, n.46, p.319-350, 1960.

MALAVOLTA, E. Elementos de nutrição mineral de plantas. São Paulo: Agronômica Ceres, 1980. $251 \mathrm{p}$.

MALAVOLTA, E.; KLIEMANN, H.J. Desordens nutricionais no cerrado. Piracicaba: POTAFOS, 1985. $136 \mathrm{p}$.
McPHARLIN, I.R.; AYLMORE, P.M.; JEFFERY, R.C. Nitrogen requirements of lettuce under sprinkler irrigation and trickle fertigation on a spearwood sand. Journal of Plant Nutrition, New York, v.18, n.2, p.219-241, 1995.

NOGUEIRA, F.D.; FAQUIN, V.; PAULA, M.B. Solos, calagem e adubação para brássicas. Informe Agropecuário, Belo Horizonte, v.9, n.98, p.21 29, 1983.

OLIVEIRA, J.P. Efeitos de alumínio e de micronutrientes no feijoeiro (Phaseolus vulgaris $L$.). 1980. 196 f. Tese (Doutorado em Fitotecnia) - Escola Superior de Agricultura "Luiz de Queiroz", Piracicaba, SP.

POULSEN, N.; SORENSEN, J.N.; JOHANSEN, A.S. Influence on growth conditions on the value of crisphead lettuce. 2. Weight losses during storage as affected by nitrogen, plant age and cooling system. Plant Foods for Humam Nutrition, v.46, n.1, p.13-18, 1994.

RESENDE, G.M.; YURI, J.E.; MOTA, J.H.; FREITAS, S.A.C.; RODRIGUES JÚNIOR, J.C.; SOUZA, R.J.; CARVALHO, J.G. Adubação foliar com silício em alface americana (Lactuca sativa L.) em cultivo de verão. In: CONGRESSO BRASILEIRO DE OLERICULTURA, 43., 2003, Recife, PE. Horticultura Brasileira, Brasília, v.20, n.2, p.374, 2003a. Suplemento 1.

RESENDE, G.M.; YURI, J.E.; MOTA, J.H.; SOUZA, R.J.; FREITAS, S.A.C.; RODRIGUES JÚNIOR, J.C. Efeitos de tipos de bandejas e idade de transplantio de mudas sobre o desenvolvimento e produtividade de alface americana. Horticultura Brasileira, Brasília, v.21, n.3, p.562567, 2003 b.

RICCI, M.S.F. Crescimento e teores de nutrientes em cultivares de alface (Lactuca sativa L.) adubados com vermicomposto. 1993. $101 \mathrm{f}$. Dissertação (Mestrado em Solos e Nutrição de Plantas) - Universidade Federal de Viçosa, Viçosa, MG RICCI, M.S.F.; CASALI, V.W.D.; CARDOSO, A.A.; RUIZ, H.A. Teores de nutrientes em duas cultivares de alface adubadas com composto orgânico. Pesquisa Agropecuária Brasileira, Brasília, v.30, n.8, p.1035-1039, 1995.

SANCHEZ, C.A.; BURDINE, V.L.; GUZMAN, V.L.; HALL, C.B. Yield, quality, and leaf nutrient composition of crisphead lettuce as affect by N, $\mathrm{P}$, and $\mathrm{K}$ on histosols. Proceedings Florida Horticultural Society, v.101, n.1/3, p.346-350, 1988.

TEI, F.; BENINCASA, P.; GUIDUCCI, M. Effect of nitrogen availability on growth and nitrogen uptake in lettuce. Acta Horticulturae, n.533, p.385392, 2000.

THOMPSON, T.L.; DOERGE, T.A. Nitrogen and water interactions in subsurface trickle-irrigated leaf lettuce: I. Plant response. Soil Science Society of American Journal, v.60, n.1, p.163-168, 1996a. THOMPSON, T.L.; DOERGE, T.A. Nitrogen and water interactions in subsurface trickle-irrigated leaf lettuce: II. Agronomic, economic, and environmental outcomes. Soil Science Society of American Journal, v.60, n.1, p.168-173, 1996b.

WHITAKER, T.W.; RYDER, J.E. Lettuce production in the United States. Washington: USDA, 1974. 43 p. (USDA. Washington Agriculture Handbook, 221) 
YURI, J.E. Avaliação de cultivares de alface americana em duas épocas de plantio e dois locais do Sul de Minas Gerais. 2000. 51 f. Dissertação (Mestrado em Fitotecnia) - Universidade Federal de Lavras, Lavras, MG.

YURI, J.E.; RESENDE, G.M.; MOTA, J.H.; FREITAS, S.A.C.; RODRIGUES JUNIOR, J.C.; SOUZA, R.J.; CARVALHO, J.G. Resposta da alface americana (Lactuca sativa L.) a doses e épocas de aplicação silicato de potássio em cultivo de inverno. In: CONGRESSO BRASILEIRO DE OLERICULTURA, 43., 2003, Recife, PE. Horticultura Brasileira, Brasília, v.20, n.2, p.372, 2003b. Suplemento 1.
YURI, J.E.; RESENDE, G.M.; MOTA, J.H.; GONÇALVES, L.D.; SOUZA, R.J. Doses e épocas de aplicação de molibdênio na produção e qualidade de alface. Horticultura Brasileira, Brasília, v.22, n.3, p.589-592, 2004a.

YURI, J.E.; RESENDE, G.M.; MOTA, J.H.; RODRIGUES JÚNIOR, J.C.; SOUZA, R.J.; CARVALHO, J.G. Comportamento de alface americana em função do uso de doses e épocas de aplicação de boro em cultivo de inverno. Horticultura Brasileira, Brasília, v.22, n.3, p.593-596, 2004b.
YURI, J.E.; SOUZA, R.J.; FREITAS, S.A.C.; RODRIGUES JÚNIOR, J.C.; MOTA, J.H. Comportamento de cultivares de alface tipo americana em Boa Esperança. Horticultura Brasileira, Brasília, v.20, n.2, p.229-232, 2002.

ZITO, R.K.; FRONZA, V.; MARTINEZ, H.E.P PEREIRA, P.R.G.; FONTES, P.C.R. Fontes de nutrientes, relações nitrato:amônio e molibdênio em alface (Lactuca sativa $\mathrm{L}$.) produzida em meio hidropônico. Revista Ceres, Viçosa, v.41, n.236, p.419-430, 1994 